\title{
ALLEN NEWELL 1927-1992, IN MEMORIAM
}

\author{
Hans Berliner \\ School of Computer Science \\ Carnegie-Mellon University \\ Pittsburgh
}

\begin{abstract}
Allen Newell died on July 19, 1992, after a long struggle with cancer. He was my friend and my mentor, the most significant force in my life. His passing has created a void in me and at Carnegie-Mellon University that will be impossible to fill. He was not only a great scientist, but an even greater human being, having time for everyone and almost everything.
\end{abstract}

It was amazing how one could call up Allen in the late hours and not only have him be willing to talk, but to spend considerable amounts of time on whatever happens to be the subject of conversation. All this with good humor and never a sense that one was intruding on the limited time of this great man.

Allen Newell is known to most of us as a person who was there at the beginning of Artificial Intelligence and who had written several papers on computer chess in those early days. His first paper on the subject (Newell, 1955) was a beautiful piece of analysis, well ahead of its time. Even today, we are not able to do the things that he shows very clearly that humans must do in playing chess. I consider this a piece of obligatory reading, to be repeated every 3-4 years, just to remind us of what still needs to be done.

The other chess paper that he co-authored (Newell et al., 1958) was the description of the early NSS chess program. This program undoubtedly was the worst of the three early programs (NSS, IBM, and Los Alamos). However, the paper bristled with ideas. Not only was this a use of the new programming language IPL-V which pioneered the use of list-processing, but it also contained the first mention in the literature of the idea of alphabeta, something that had escaped the great minds of the time that had written about game-playing and computer chess. These included von Neumann, Shannon and Turing. Without alpha-beta, computer chess would still be in the backwoods somewhere.

These were the overt contributions of Allen Newell to computer chess. He had many students (myself among them) who endeavored to make their contributions to computer chess. I have to confess that his ideals for this work have turned out to be too lofty. If a symbolic thinking computer chess agent is to be, it will have to have a great deal of grungy support from routines that gather incredible amounts of knowledge and know how to analyze it. I believe Allen always underestimated this facet of things. However, it did not keep him from being the World's greatest devil's advocate. Even in the halcyon days of Hitech, when I went to report progress and ideas that were in the works, I could always count on him to have some incisive insight that no one on the team had had, and that was worth paying attention to before proceeding further. He was a part of everything that went on in Computer Science at CMU.

These are the details of his scientific life as can be viewed by a historian. However, Allen was much more than that. Without him it would almost certainly not have been possible to get U.S. government funding for something as unapplicable as chess. He was able to sway short-sighted funding agencies to his way of thinking: that progress in computer chess was progress in understanding intelligence. I have often heard him argue that even when machines play chess in ways that are different than humans, it still exposes the differences, and contributes to a general understanding of what intelligence is, and to what human failings are.

Lest one think that he only dreamed idealized dreams, let me hasten to add that Allen Newell was the prime force in getting funding agencies to support research on speech understanding. That machines that can understand human speech can now be bought at a very reasonable price is something that would not have happened without him. Success at speech understanding opened the door for investigations of vision and all its complexities.

Allen Newell was never afraid to ask the hard questions. That his own answers were only partial, and that no one in the field came up with good answers never perturbed him. These were questions that needed to be asked 
and his asking them gave direction to the field of AI. Now we find that there were many in addition to Allen Newell, initiators too, but after him and subsequent to his ideas. Still, I can think of no one who has had more to do with nurturing its welfare, and giving it a continuous sense of direction than Allen Newell. We will all miss him.

\section{References}

Newell, A. (1955). The Chess Machine: An Example of Dealing with a Complex Task by Adaptation. Proceedings Western Joint Computer Conference, pp. 101-108.

Newell, A., Shaw, J.C. and Simon, H.A. (1958). Chess Playing Programs and the Problem of Complexity. IBM Journal of Research and Development, October, 2, pp. 320-335. Reprinted in Computers and Thought (eds. E.A. Feigenbaum and J. Feldman), pp. 39-70 (1963). McGraw-Hill, New York.

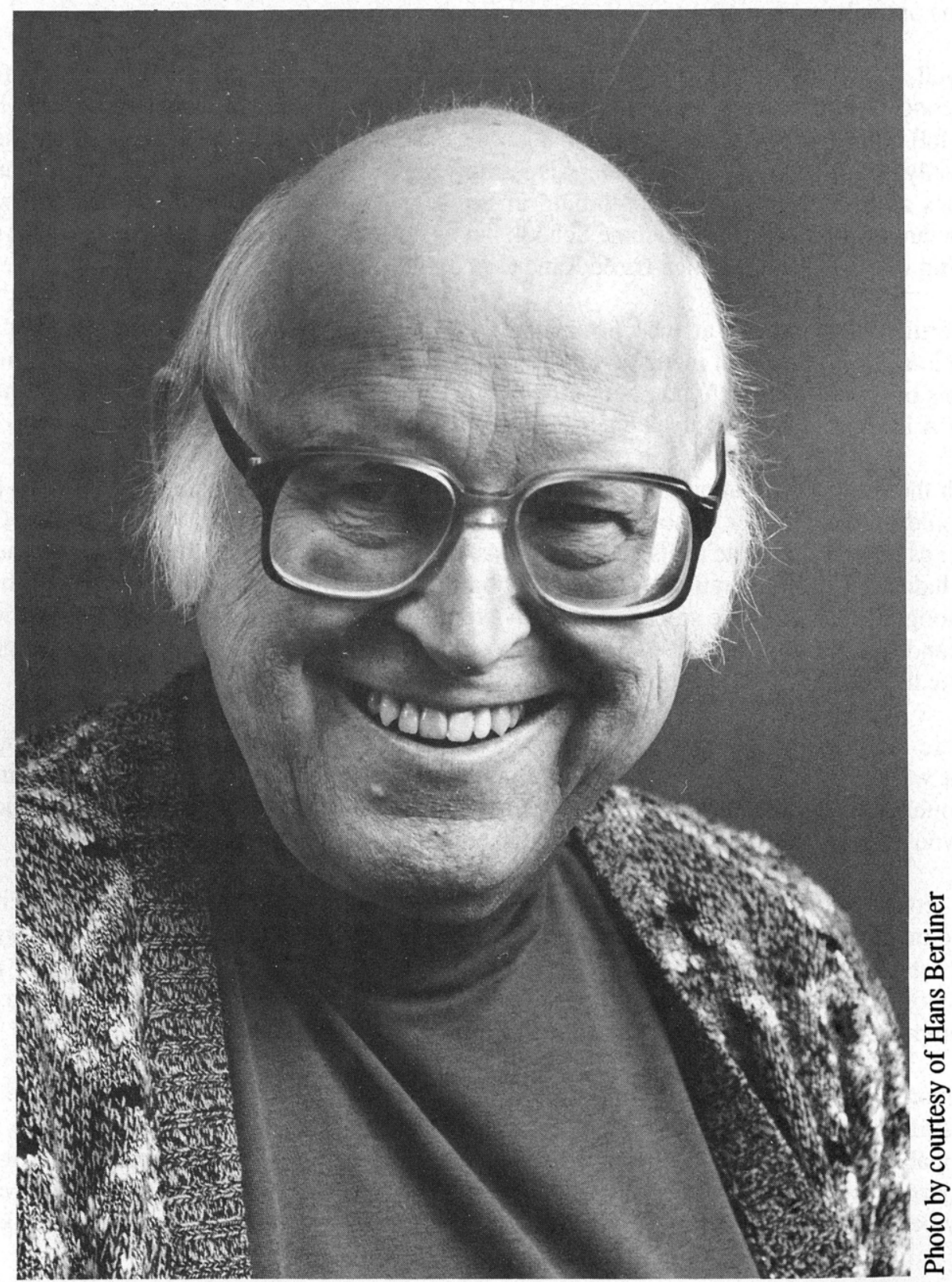

Allen Newell, 1927-1992 